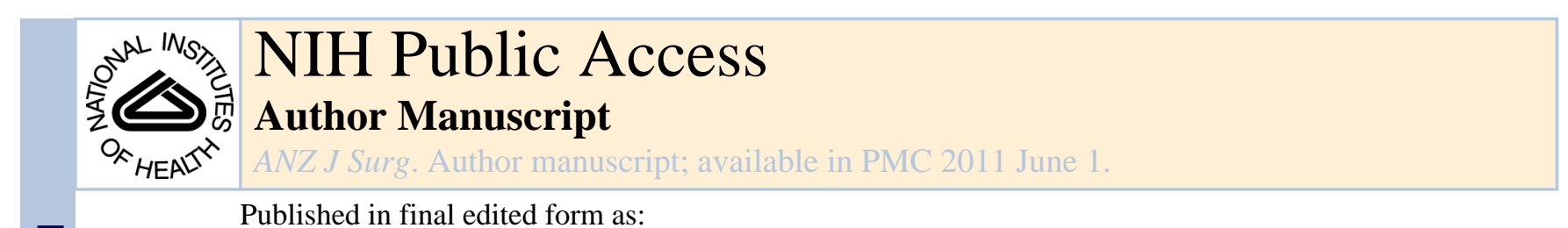

Published in final edited form as:

ANZ J Surg. 2010 June ; 80(6): 473-474. doi:10.1111/j.1445-2197.2010.05329.x.

\title{
Blood clot cast of the tracheobronchial tree
}

\author{
Luc G. T. Morris, MD, Mike Sheu, MD, and Daniel M. Zeitler, MD \\ Department of Otolaryngology-Head and Neck Surgery, New York University Medical Centre, \\ New York, New York, USA
}

A 57-year-old woman on chronic prednisone therapy for a history of progressive systemic lupus erythematosus with pulmonary involvement was admitted to the intensive care unit with dyspnea. She was diagnosed with pneumocystis carinii pneumonia and required intubation due to acute respiratory failure. Ultimately, due to prolonged ventilator support, a tracheotomy was performed after 22 days of peroral endotracheal intubation. The patient was subsequently weaned off of ventilator support to tracheotomy collar and transferred to a ward unit. Two weeks post-operatively, the tracheotomy tube was uneventfully downsized.

Three weeks postoperatively, the patient experienced an episode of massive haemoptysis, 2 $\mathrm{L}$ in volume. The patient was emergently taken to the operating room. The patient became difficult to bag ventilate and became hypoxic. Flexible bronchoscopy revealed large blood clots in the tracheobronchial tree, which could not be removed with flexible instruments. A rigid bronchoscopy was performed, and clot extracted with rigid cupped forceps (Fig. 1). At this point, oxygenation was improved. There was no bleeding source identifiable in the soft tissues of the neck or in the trachea. An arteriogram of the aortic arch, innominate artery, and carotid arteries was performed by the vascular surgery service, and was negative for extravasation. A CT scan of the neck and chest revealed a cavitary lesion of the right upper lobe, consistent with mycetoma. A bronchial artery angiogram was then performed by the interventional radiology service. Extravasation was observed from a branch of the right bronchial artery, which was embolised.

The blood clot cast in this patient's tracheobronchial tree impaired adequate ventilation until it was extracted. Rigid bronchoscopy and instrumentation permitted en bloc removal and immediate improvement in oxygenation. We have only identified one prior published photograph in the literature of a partial bronchial blood clot cast. ${ }^{1}$

\section{References}

1. Coonar A. Blood clot cast of the bronchial tree. Eur. J. Cardiothorac. Surg 2005;28:490. [PubMed: 16054830] 


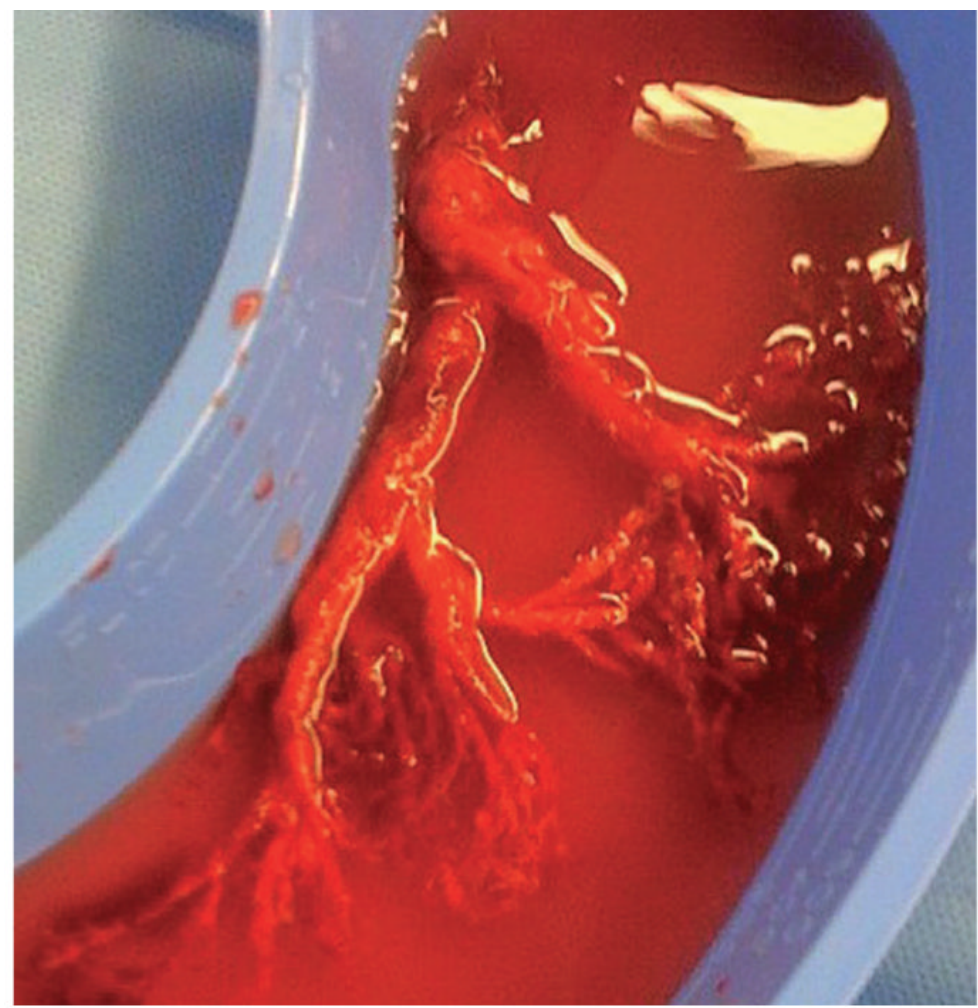

Fig. 1.

Blood clot cast removed via rigid bronchoscopy. 